\title{
Circular Economy in Hydraulic Engineering
}

\author{
Paweł Falaciński* \\ Department of Hydro-Engineering and Hydraulics, Warsaw University of Technology, Poland
}

*Corresponding author: Paweł Falaciński, Department of Hydro-Engineering and Hydraulics, Warsaw University of Technology, Poland.

\author{
Received Date: January 09, 2019 \\ Published Date: January 18, 2019
}

\section{Opinion}

The growing awareness of threats to the natural environment puts a lot of emphasis on the development of environmentally friendly technologies and expects that economic and civilization development will take place in a sustainable way. In addition to technical tools, strategic concepts are developed with a complex legal, economic and educational character. Their aim is to shape a responsible attitude of societies to the protection of the environment and natural resources. One of such concepts is the near zero waste economy -Circular Economy, which is based on the desire to re-use products, including by-products. This requires not only changing habits, legal norms and appropriate economic tools preferring secondary materials, but above all developing appropriate technologies, because only they can make the secondary one as good as the original one. In the context of these assumptions, the present moment the use of waste materials in Hydraulic Engineering becomes both necessary and common (economically justified). It should be mentioned several areas in which waste materials are used.

The first, probably the most serious, are binders-cements. The use of cements with the addition of silica ashes and blast-furnace slag is a standard in the context of the implementation of cubature objects, which are the hallmark of Hydraulic Engineering. The use of both ash and slag allows you to deal with the effects of heat of hydration, as well as contraction when binding concrete mix. In addition, concretes based on these cements are characterized by a higher resistance to the surrounding environment aggressive environment. The second area of application of waste materials are seals of hydro-engineering structures using cut-off walls. Cut-off walls made of hardening slurries are implemented in various types of facilities, such as flood embankments, water dams, embankments of landfills, retention reservoirs and others. In order to improve the tightness of the hardening slurries, ash from conventional combustion, fluidization from hard and brown coal as well as blast furnace slag are added quite often to their composition. These materials are a special addition because they are mineral in nature and have binding properties. So, they can fulfill not only the role of the filler, but also an additional binder. The current research on hardening slurries with the addition of these waste materials has shown an improvement in the resistance of suspensions to corrosion, in the case of some aggressiveness of the water environment and capillary-diffusion transport of aggressive substances. This is particularly important when antifiltration apertures serve to separate groundwater from sources of pollution. The measure of leak tightness of hardening slurries is their hydraulic conductivity. The latter is primarily conditioned by the porosity structure and the characteristics of the filtrating medium. Apart from the temperature and the physical features of the liquid (viscosity and density), its chemical characteristics are equally important, and in particular its capacity to react with slurry ingredients (corrosive processes). These processes can significantly change the structure of the material and its characteristics, including hydraulic conductivity.

Another area of application for waste materials may be earth hydro-engineering structures. Two different waste materials can be used for the implementation of this type of object - by-products of fluidized bed combustion of hard coal (UPS) and coal slate (socalled black). The first material comes from the power industry and the second from coal mining. Each of them separately finds a variety of applications limiting the amount of slate deposited on heaps and UPS deposited in landfills. The idea of joint use of slate and UPS comes from hydraulic and civil engineering. Coal enrichment technology is wet technology and slate - treated after recovery as waste is strongly hydrated. In order to properly incorporate it into earth structures it should be dried and lead to so called optimal humidity due to compaction. In turn, UPS is a dry, relatively fine granular mineral mixture, with a few percent share of unburned coal and desulphurization products, which gives it high water demand. The combination of wet shale and dry UPS leads to anthropogenic soil mixtures with many favorable 
geotechnical features. This, generally speaking, a beneficial solution, encounters some application difficulties due to the fact that slate and UPS interactions are not limited to water exchange and physical processes. Due to the rich chemistry, especially UPS, complicated and long-lasting chemical changes occur in the slateash mixtures, leading to usually unfavorable volume changes of the material. Water has a significant share in these processes, the content of which in the mixture is in real conditions not only due to the production of a slate mixture and UPS, but also the working conditions of this material after being incorporated into a specific structure subjected, for example, to atmospheric interactions. It is obvious that the use of waste materials during the implementation of hydro-engineering structures must be preceded by an in-depth study of the applicability of individual types of waste. Use without proper knowledge supported by research can, of course, bring the opposite effect to the expected one.

In summary, the use of waste products may not only be beneficial in various technical and technological aspects, but also in economic and environmental terms. The largest possible disposal of stored waste materials contributes to active environmental protection by reducing the consumption of natural resources and reducing the amount of waste.

\section{Acknowledgment}

None.

\section{Conflict of Interest}

No conflict of interest. 